\title{
Mechanisms Underlying Taurine Protection Against Glutamate-Induced Neurotoxicity
}

\author{
Hai-Bo Ye, Hai-Bo Shi, Shan-Kai Yin
}

\begin{abstract}
Taurine appears to exert potent protections against glutamate (Glu)-induced injury to neurons, but the underlying molecular mechanisms are not fully understood. The possibly protected targets consist of the plasma membrane and the mitochondrial as well as endoplasmic reticulum (ER) membranes. Protection may be provided through a variety of effects, including the prevention of membrane depolarization, neuronal excitotoxicity and mitochondrial energy failure, increases in intracellular free calcium $\left(\left[\mathrm{Ca}^{2+}\right] i\right)$, activation of calpain, and reduction of Bcl-2 levels. These activities are likely to be linked spatially and temporally in the neuroprotective functions of taurine. In addition, events that occur downstream of Glu stimulation, including altered enzymatic activities, apoptotic pathways, and necrosis triggered by the increased $\left[\mathrm{Ca}^{2+}\right] i$, can be inhibited by taurine. This review discusses the possible molecular mechanisms of taurine against Glu-induced neuronal injury, providing a better understanding of the protective processes, which might be helpful in the development of novel interventional strategies.
\end{abstract}

RÉSUMÉ: Mécanismes sous-jacent à l'effet protecteur de la taurine contre la neurotoxicité induite par le glutamate. La taurine peut exercer une protection puissante contre le dommage neuronal induit par le glutamate (Glu) mais les mécanismes moléculaires sous-jacents ne sont pas bien compris. Les cibles potentiellement protégées sont la membrane cellulaire, la membrane mitochondriale et celle du réticulum endoplasmique, sur lesquelles le fait d'exercer une protection au moyen de différents effets dont la prévention de la dépolarisation de la membrane, l'excitotoxicité et la défaillance énergétique mitochondriale, l'augmentation du calcium libre intracellulaire ([Ca2+])i, l'activation de la calpaïne et la diminution des niveaux de Bcl-2. Ces activités sont vraisemblablement liées au point de vue spatial et temporel dans les fonctions de neuroprotection qu'exerce la taurine. De plus, les événements qui surviennent en aval de la stimulation par le Glu dont une altération des activités enzymatiques et des voies apoptotiques et une nécrose induite par l'augmentation de $([\mathrm{Ca} 2+])$ i, peuvent être inhibées par la taurine. Dans cette revue, nous discutons des mécanismes moléculaires possibles de la taurine pour contrer le dommage neuronal induit par le Glu afin de mieux comprendre lequel pourrait être utile dans le développement de nouvelles stratégies d'intervention.

Can J Neurol Sci. 2013; 40: 628-634

Taurine (2-aminoethanesulfonic acid) is an abundant $\beta$-amino acid found in most mammalian tissues, such as the cardiac muscles and brain ${ }^{1}$. Taurine has an important role in certain aspects of mammalian development, especially as a trophic factor in the development of the central nervous system $(\mathrm{CNS})^{2,3}$. The physiological role of taurine has received considerable attention since the finding that cats fed a diet deficient in taurine develop central retinal degeneration ${ }^{4}$, skeletal muscle disorders ${ }^{5}$ and cardiomyopathy ${ }^{6,7}$. These pathologic conditions could be reversed if taurine intervention was given within a critical time window ${ }^{8}$.

The notion that taurine is a neurotransmitter in the mammalian CNS has been supported by following lines of evidence: 1 . The presence of a specific enzyme, namely cysteic/ cysteine sulfinic acid decarboxylase, responsible for taurine biosynthesis in the brain ${ }^{9} .2$. Release of taurine has been shown to be either calcium independent or calcium dependent ${ }^{10} .3$. Taurine has been shown to elicit neuronal hyperpolarization, presumably through its action of opening the chloride channels in neurons of the hippocampus ${ }^{11}$, cerebellum ${ }^{12}$, and anteroventral cochlear nucleus ${ }^{13} .4$. The presence of specific taurine receptors has been demonstrated ${ }^{14}$. 5. The presence of a taurine transporter system for inactivation of its function has also been reported ${ }^{15}$.
In summary, taurine may primarily be accepted as a neurotransmitter in the mammalian CNS.

Taurine can be synthesized from methionine and cysteine within the liver ${ }^{16,17}$. Although mammals are able to synthesize taurine endogenously, taurine biosynthesis is high in rodents and low in humans. As a consequence, dietary taurine uptake is the major method of taurine supply in humans, and dietary deficiency may induce problems in physiological processes ${ }^{18}$. The whole-body taurine content then is derived in three different ways: (1) direct taurine intake from the diet; (2) kidney reabsorption; and (3) taurine de-novo synthesis by the liver and alternative tissues ${ }^{18}$. In addition, taurine has been shown to have many other important physiologic functions, including maintenance of the structural integrity of plasma membrane ${ }^{19}$,

From the Department of Otorhinolaryngology, Affiliated Sixth People's Hospital of Shanghai Jiaotong University, Shanghai, China.

Received June 25, 2004. Final Revisions Submitted January 21, 2004. Correspondence to: Hai-Bo Shi, Department of Otorhinolaryngology, Affiliated Sixth People's Hospital of Shanghai Jiaotong University, 600 Yishan Road, Shanghai 200233, China. Email: haibo99@hotmail.com. 
modulation of calcium homeostasis ${ }^{20}$, antioxidant activity ${ }^{21}$, modulation of synaptic activity in the brain ${ }^{2,3,22}$, anticonvulsant activity $^{23}$, osmoregulatory activity ${ }^{24,25}$. The protection of neurons against glutamate (Glu)-induced excitotoxicity has been considered as its essential action ${ }^{26}$. Clinically, taurine has been used with varying degrees of success in the treatment of various conditions, including cardiovascular diseases, epilepsy and other seizure disorders, macular degeneration, hepatic disorders, cystic fibrosis, stroke, Alzheimer's disease, Huntington's disease, and brain ischemia ${ }^{27-31}$.

Glutamate is the major excitatory neurotransmitter in the mammalian $\mathrm{CNS}^{32}$ and plays important roles in neuronal differentiation, migration, and survival in the developing brain ${ }^{33-}$ ${ }^{35}$, as well as in synaptic maintenance and plasticity ${ }^{36}$. Activation of Glu receptors results in extracellular calcium influx and mobilization of additional calcium from intracellular stores ${ }^{20}$. However, excessive stimulation by Glu causes cell damage, and even cell death, in a phenomenon known as neuronal excitotoxicity ${ }^{33,34,37}$. Intense glutamatergic insult may induce a loss of cellular homeostasis with acute mitochondrial dysfunction leading to massive energy failure ${ }^{38}$. Milder glutamatergic insults, however, cause cell death ascribed to various cell death pathways, including a gamut of molecular players cysteine proteases, mitochondrial endonucleases, peroxynitrite, poly ADP ribose polymerase and glyceraldehyde phosphate dehydrogenase in excitotoxic neurodegeneration ${ }^{39}$.

An important function of taurine is that it is neuroprotective ${ }^{40}$. It is generally believed that taurine protects neurons against Gluinduced neurotoxicity by preventing Glu-induced membrane depolarization, excitotoxicity, increases in level of intracellular free calcium $\left(\left[\mathrm{Ca}^{2+}\right] i\right)$, mitochondrial energy failure, activation of calpain, reduction of Bcl-2 levels, and apoptosis ${ }^{41}$. These phenomena are probably linked spatially and temporally in the neuroprotective functions of taurine. However, there is a lack of information regarding the specific impacts of taurine on intracellular signaling and cell death pathways, particularly in vivo. A better understanding of the molecular process underlying the neuroprotective function of taurine against Glu-induced neuronal injury would facilitate the development of novel interventional strategies to protect against neurotoxicity.

\section{Taurine and membranes}

Taurine acts through several mechanisms to limit the degree of lipid peroxidation (LP) and membrane damage. Recent studies have shown that preliminary treatment with taurine decreases the rates of lipid peroxide formation and lactate accumulation in the brain, and restores membrane $\mathrm{Na}^{+}, \mathrm{K}^{+}-$ ATPase activity during acute severe hypoxia ${ }^{42}$. Hypoxia-induced activation of LP has been reported by many researchers ${ }^{43,44}$. It has also been proposed that increased cytosolic $\mathrm{Ca}^{2+}$ is responsible for LP activation in various tissues under hypoxic conditions. The regulation of membrane $\mathrm{Na}^{+}, \mathrm{K}^{+}$-ATPase activity by taurine explains the effects of taurine on the membrane binding of $\mathrm{Ca}^{2+}$ and the modification of the membrane lipid order, conformation, and dynamics. Taurine is also observed to act as an antioxidant of peroxynitrite to decrease LP and thus affect liver plasma membrane $\mathrm{Na}^{+}, \mathrm{K}^{+}$-ATPase by restoring its activity ${ }^{45}$. Furthermore, taurine deficiency has been implicated in disturbances of the lipid membrane structure and membrane fatty acid composition ${ }^{46}$. Taurine is also known to interact with specific plasma membrane proteins ${ }^{47}$ and to prevent phospholipase-mediated and oxidation-mediated membrane damage through its membrane stabilizing activity ${ }^{48}$, while membrane damages were considered as an inevitable result of Glu-induced excitotoxicity.

Furthermore, $\mathrm{Wu}$ et $\mathrm{al}^{49}$ have shown that taurine protects neurons against Glu excitotoxicity by direct preventing Gluinduced membrane depolarization. Taurine affects the opening of chloride channels by interactions with $\gamma$-aminobutyric acid $(\mathrm{GABA})_{\mathrm{A}}$ receptors $^{13}$, glycine receptors ${ }^{50}$ or taurine receptors ${ }^{49}$, thereby preventing the Glu-induced increase in calcium influx and other downstream events. This hypothesis, that taurine inhibits the Glu-induced calcium influx by affecting membrane potential, is supported by several observations ${ }^{49,51}$. First, taurine inhibits calcium influx through various voltage-gated calcium channels (VGCCs). Second, taurine does not directly inhibit calcium influx through NMDA receptor calcium channels unless $\mathrm{Mg}^{2+}$ is present, which renders the NMDA receptor depolarization-dependent. Third, taurine inhibits Glu-induced membrane depolarization in cultured neurons.

\section{Taurine and mitochondria}

Mitochondria have two major functions: the production of cellular energy and the sequestration of calcium ions. They also play key roles in the regulation of calcium homeostasis and apoptosis $^{52-55}$. Glu excitotoxicity begins with excessive calcium influx through the L-, N-, and P/Q-type VGCC and NMDA receptor calcium channels, leading to intracellular calcium overload, which can activate the release of cytochrome $\mathrm{c}$ and activate caspases, thereby leading to apoptosis ${ }^{56,57}$. Conversely, the release of cytochrome $\mathrm{c}$ impairs mitochondrial function, as cytochrome $\mathrm{c}$ is one of the components of the oxidative phosphorylation chain. Impairment of mitochondrial function disrupts ATP synthesis, and a lack of ATP leads to dysfunction of ion channels, resulting in irreversible mitochondrial dysfunction and, ultimately, cell death ${ }^{49,58,59}$.

The mitochondrial pathway of apoptosis is involved in the excitotoxic response to Glu and, as such, the response to cellular stress induces the mitochondrial pathway though the initial action of caspase- $9^{60,61}$. Furthermore, imbalances between Bcl-2 and Bax lead to the formation of Bax homodimers, which target the mitochondria and cause the release of cytochrome c, resulting in the activation of apoptotic protease activity factor-1 (Apaf-1), which in turn activates the caspase cascade that leads to apoptosis $^{62}$. Moreover, Glu-induced neuronal necrosis is preceded by a rapid increase in the cytoplasmic free calcium concentration $^{63}$, in which mitochondria play an important role by releasing internal free calcium.

Recent studies have confirmed that pre-treatment of cerebellar granule cells with taurine significantly counteracts Glu excitotoxicity ${ }^{20}$. This counteraction is mediated through regulation of cytoplasmic $\left[\mathrm{Ca}^{2+}\right] i$ and intra-mitochondrial calcium homeostasis, as determined by Fluo- 3 and ${ }^{45} \mathrm{Ca}^{2+}$ uptake assays. Furthermore, overall mitochondrial function is increased in the presence of taurine, as assessed by tests for rhodamine accumulation by mitochondria and total cellular ATP levels ${ }^{64}$. Taurine also increases the capacity of mitochondria to sequester calcium when the cells are stimulated and the level of 
cytoplasmic calcium is drastically increased. Thus, taurine reduces Glu excitotoxicity through both the enhancement of mitochondrial function and the regulation of intracellular (cytoplasmic and intra-mitochondrial) calcium homeostasis ${ }^{20}$. The functional consequence of regulating $\left[\mathrm{Ca}^{2+}\right] i$ is that the mitochondria are protected from the damaging effects of calcium overload and subsequent neuronal death. The role of taurine in modulating mitochondrial calcium homeostasis may be of particular importance under pathologic conditions characterized by excessive calcium overload ${ }^{20,64}$.

Mitochondrial protection by taurine may not be merely a consequence of calcium regulation during excitotoxicity. Taurine could have a trophic role for neuronal cells through the enhancement of their mitochondrial functions and, thus, their bioenergetic capacity. Consistent with this, taurine has been identified as a survival-promoting factor for cerebellar granule cells ${ }^{44}$. In addition, taurine serves as a regulator of mitochondrial protein synthesis, thereby enhancing electron transport chain activity and protecting the mitochondria against excessive superoxide generation ${ }^{42,43}$. The major components of superoxide generation in the mitochondria are complexes I and III, and it is widely accepted that slowing electron flux through the respiratory chain diverts electrons from complexes I and III to an alternate acceptor, such as oxygen. Taurine prevents the diversion of electrons into superoxide generation by improving the functioning of the electron transport chain.

Takatani et $\mathrm{al}^{54,65}$ have demonstrated that taurine prevents ischemia-induced apoptosis of cardiomyocytes, and that this is accompanied by the inactivation of caspase- 9 and caspase- 3 . Taurine treatment inhibited Apaf-1/caspase-9 apoptosome formation without preventing mitochondrial dysfunction under ischemic conditions. To act as a neuroprotectant, taurine must interact with targets linked to calcium and mitochondrial metabolism ${ }^{20}$ or downregulate components of the apoptosis cascade, such as caspase- $3^{55,66}$ and caspases- 8 and $-9^{67}$. In vivo taurine has been demonstrated to protect the brain against experimental stroke in a dose-dependent manner ${ }^{55}$, and taurine could reduce ischemic brain injury by blocking mitochondriamediated cell death pathways by inhibiting the activation of calpain and caspase- 3 , reducing the degradation of $\alpha$ II-spectrin, and attenuating necrotic and apoptotic cell death in the penumbra and core ${ }^{68}$.

Therefore, these two functions for taurine: enhancement of mitochondrial function and regulation of intracellular (cytoplasmic and mitochondrial) calcium homeostasis, and possibly others functions, probably participate in neuronal survival and protection against Glu excitotoxicity. Therefore, taurine may serve as an endogenous neuroprotective molecule against mitochondrial dysfunction. ${ }^{20}$

\section{Taurine and endoplasmic reticulum (ER) membranes}

The ER is an important subcellular organelle that is responsible for intracellular calcium homeostasis, protein secretion and lipid biosynthesis ${ }^{69-71}$, and there is increasing evidence that ER stress plays a crucial role in hypoxia/ ischemiainduced cell dysfunction ${ }^{72,73}$. Cerebral hypoxia and/or ischemia result in a decrease of glucose and oxygen which in turn induce the release of Glu at the presynaptic level. The high levels of Glu and the subsequent activation of glutamatergic postsynaptic receptors are the main components in a cascade of sequential molecular events that culminates the death of neurons ${ }^{63,74}$. Pan et al $^{75,76}$ recently demonstrated that taurine may exert its protective effect on cortical neurons through suppression of ER stress induced by Glu. When neurons are exposed to Glu, the homeostasis in neuronal cultures is disturbed, initiating dimerization and autophosphorylation of ER membrane proteins, kinase-like ER kinase (PERK) and inositol requiring enzyme 1 (IRE1). Transcription factor 6 (ATF6) (P90) is activated by limited proteolysis after its translocation from the ER to the Golgi apparatus to form cleaved ATF6 (P50). All of these three pathways induce up-regulation of $\mathrm{C} / \mathrm{EBP}$ homologous protein (CHOP) which would initiate cell death. Taurine treatment greatly inhibits ATF6 and IRE1 pathways after Glu over a longer time frame. In contrast, activation of the initiation of PERK pathway is delayed by taurine under conditions of brief Glu exposure ${ }^{75}$.

\section{Taurine and intracellular calcium homeostasis}

The $\left[\mathrm{Ca}^{2+}\right] i$ is maintained by calcium sequestration into internal calcium storage pools, as well as by pumping out of calcium to the extracellular space by a calcium-ATPase at a submicromolar concentration. When neurons are stimulated by Glu, the $\left[\mathrm{Ca}^{2+}\right] i$ is increased due to an influx of calcium from extracellular sources via various calcium channels, as well as by the release of calcium from the internal calcium storage pools ${ }^{49,77}$.

Taurine has been shown to be involved in the regulation of calcium homeostasis in many tissues, including the heart ${ }^{6,7}$, brain $^{78}$, and retina ${ }^{79}$, as well as in cultured myocardial cells ${ }^{80}$, cultured spiral ganglion neurons, the outer hair cells of the inner ear $^{81,82}$, and cultured neuronal cells ${ }^{20,44,54}$. The primary mechanism of the neuroprotective activity of taurine is thought to be its action in regulating calcium homeostasis, i.e., preventing or reducing Glu-induced increases in $\left[\mathrm{Ca}^{2+}\right] i^{44,83}$, which is supported by many other findings.

It has been reported that taurine may inhibit calcium influx through the reverse mode of the $\mathrm{Na}^{+} / \mathrm{Ca}^{2+}$ exchanger, the activity of which is membrane potential-dependent ${ }^{83}$. The function of the $\mathrm{Na}^{+} / \mathrm{Ca}^{2+}$ exchanger is to move $\mathrm{Ca}^{2+}$ out of cell at the resting membrane potential; the exchanger reverses mode to facilitate $\mathrm{Ca}^{2+}$ influx under depolarizing conditions, such as Glu stimulation ${ }^{84}$. The effect of taurine on the $\mathrm{Na}^{+} / \mathrm{Ca}^{2+}$ exchanger is, in part, due to its membrane stabilizing activity, which suggests that the neuroprotective activity of taurine is linked to its ability to prevent Glu-induced membrane depolarization ${ }^{85}$.

Recent studies have shown that when Glu-induced membrane depolarization is abolished by taurine, as measured with a voltage-sensitive dye, VGCC activity is also suppressed ${ }^{86}$. In addition to its action on membrane potential, taurine may inhibit channel activity through its effect on protein phosphorylation ${ }^{49}$. It has been known that Glu stimulation activates metabotropic Glu receptors, which activate phospholipase C (PLC), resulting in an increase in inositol triphosphate $\left(\mathrm{IP}_{3}\right)$ formation and $\mathrm{IP}_{3}$ mediated $\mathrm{Ca}^{2+}$ release from internal $\mathrm{Ca}^{2+}$ storage pools. When the metabotropic taurine receptors (mTauR) are activated by taurine, the coupled inhibitory G-proteins $\left(\mathrm{G}_{\mathrm{o}} / \mathrm{G}_{\mathrm{i}}\right)$ are activated, resulting in the inhibition of VGCCs. Furthermore, activation of mTauR by taurine leads to inhibition of PLC activity, resulting in 
a reduction in $\mathrm{IP}_{3}$ formation and, consequently, $\mathrm{IP}_{3}$-mediated release of $\mathrm{Ca}^{2+}$ from the internal pools ${ }^{21}$.

Furthermore, taurine inhibits various VGCCs, including the $\mathrm{L}, \mathrm{N}$, and P/Q types ${ }^{86}$. The NMDA receptor calcium channel represents a major calcium influx pathway. Taurine completely blocks calcium influx through the NMDA receptor calcium channel, and rather than acting directly on the NMDA receptor, taurine exerts this effect by influencing the membrane potential ${ }^{41}$. Taurine also maintains $\left[\mathrm{Ca}^{2+}\right] i$ by inhibiting the Gluinduced release of calcium from the intracellular pools, supported by the finding that the Glu-induced increase in $\left[\mathrm{Ca}^{2+}\right] i$ in the absence of extracellular $\mathrm{Ca}^{2+}$ is inhibited by taurine ${ }^{21}$. Metabotropic Glu receptors were also reported to conversely participate in the regulation of taurine release ${ }^{87}$. Under various cell-damaging conditions, including ischemia, hypoxia and hypoglycemia, taurine release is enhanced ${ }^{40}$. The increase in extracellular taurine upon excessive stimulation of Glu receptors and under cell-damaging conditions may serve as an important protective mechanism against excitotoxicity, being particularly effective in the immature brain ${ }^{87,88}$.

\section{Taurine protection against neuronal death}

Glutamate-induced neuronal death is initiated by increases in $\left[\mathrm{Ca}^{2+}\right] i$ and sodium levels, and these are followed by the activation of catabolic enzymes, such as proteases ${ }^{43}$, phospholipases and endonucleases, the protein kinase and lipid kinase cascades, energy compromise, and the formation of ROS, leading to necrosis or apoptosis ${ }^{76}$. Some of these events induced by Glu overexcitation occur early and lead to rapid cell damage, while other factors, such as energy compromise and ROS formation, initiate a more delayed cell death process.

Both necrosis and apoptosis are involved in Glu-induced neuronal cell death ${ }^{47,48}$. One of the mechanisms of Glu-induced cell death involves calcium overload, which is known to induce mitochondrial dysfunction ${ }^{58}$, ER stress ${ }^{75}$, oxidative stress ${ }^{89}$, and activation of proteases, including calpain ${ }^{21,90}$. As $\mathrm{Ca}^{2+}$ overload triggers the release of more Glu, overactivation of the Glu receptors spreads among the neurons and further causes the release of additional calcium from intracellular stores ${ }^{77}$, thereby exacerbating excitotoxicity and contributing to the neuronal loss. Mechanisms behind Glu-induced apoptosis are: increased $\left[\mathrm{Ca}^{2+}\right] i$ following Glu stimulation, which in turn activates calpain; activation of calpain decreases the Bcl-2/Bax ratio and further results in the release of cytochrome $\mathrm{c}$ from impaired mitochondrial that leads to apoptosis ${ }^{56,57,62}$. Impairment of mitochondrial function disrupts ATP synthesis, and the consequent shortage of ATP leads to dysfunction of ion channels, resulting in intracellular ion derangements and subsequent cell death by necrosis ${ }^{20}$.

Taurine has been shown to prevent neuronal cell apoptosis and necrosis associated with Glu-induced excitotoxicity ${ }^{86}$. Taurine may exert its neuroprotective function through both extracellular and intracellular mechanisms to inhibit the Gluinduced increase in $\left[\mathrm{Ca}^{2+}\right] i^{20}$. The extracellular mechanism involves the inhibition of calcium influx through various calcium channels, including the VGCC, as well as through NMDAmediated calcium channels ${ }^{49}$. This property of taurine is attributed to its suppression of Glu-mediated depolarization through the opening of the chloride channel ${ }^{13,91}$. In addition, taurine antagonizes oxygen/glucose deprivation and reperfusioninduced edema, and these activities are dependent upon taurine transport into the cells and $\mathrm{GABA}_{\mathrm{A}}$ receptor activation and involve the activity of volume-sensitive outwardly rectifying $\mathrm{Cl}^{-}$ channels $^{92}$.

The intracellular action of taurine may be related to its protection of mitochondrial function from calcium overload and subsequent inhibition of calpain activation and all downstream events under excitatory conditions. It has been reported that Gluinduced activation of calpain directly promotes the caspase cascade by influencing the $\mathrm{Bcl}-2 / \mathrm{Bas}$ ratio $^{86}$. Furthermore, taurine treatment prevents Glu-induced cleavage of spectrin, a specific endogenous substrate of calpain, which suggests that taurine inhibits Glu-induced activation of calpain, a calciumdependent cysteine protease ${ }^{41}$. Since Bcl-2 is a substrate of calpain, taurine protects neurons from apoptosis by inhibiting Glu-induced activation of calpain and preserving the Bcl-2/Bax ratio $^{86}$. These authors have also pointed out that taurine modulates the survival/death kinase pathway equilibrium in the context of Glu stimulation.

Several studies have shown that taurine is neuroprotective against a variety of disorders ${ }^{44,49,83}$. The sequence of events that leads from Glu stimulation to apoptosis and the mode of action of taurine in preventing Glu-induced apoptosis can be summarized as follows:

1. Taurine prevents Glu-induced DNA fragmentation and nuclear condensation $^{41}$;

2. Taurine suppresses the endoplasmic reticulum stress induced by $\mathrm{Glu}^{25,75}$;

3. Taurine attenuates Glu-induced membrane depolarization $^{49,50}$;

4. Taurine prevents Glu-induced apoptosis by preventing Glu-mediated down-regulation of Bcl-286; inhibition on Glu-induced activation of calpain prevents cleavage of Bcl-2 by calpain. ${ }^{41}$;

5. Taurine protects neurons from apoptosis by restoring the balance of Bcl-2/Bax ${ }^{41}$;

6. Taurine inhibits apoptosis by preventing the formation of the Apaf-1/caspase-9 apoptosome ${ }^{54}$;

7. Taurine prevents Glu toxicity by blocking calcium overload-mediated apoptosis ${ }^{21}$ and by reducing oxidative stress-linked apoptosis ${ }^{43}$;

8. The anti-apoptotic function of taurine is linked to its ability to prevent the Glu-induced increase in $\left[\mathrm{Ca}^{2+}\right] i$ through blocking Glu-induced depolarization, resulting in the blockade of all the downstream events ${ }^{41}$.

\section{Conclusions}

There is compelling evidence that the neuroprotective effect of taurine is attributed to its functions in maintaining intracellular calcium homeostasis, membrane integrity, mitochondrial function, ER stress and as an antioxidant. This schema is depicted in the Figure and is offered as a working hypothesis. Events that occur downstream of Glu stimulation, including altered enzymatic activities, apoptotic pathways, and necrosis triggered by increased $\left[\mathrm{Ca}^{2+}\right] i$, may be inhibited by taurine. However, we still have limited knowledge on the specific effects of taurine on intracellular signaling and cell death pathways and the molecular mechanisms underlying its 


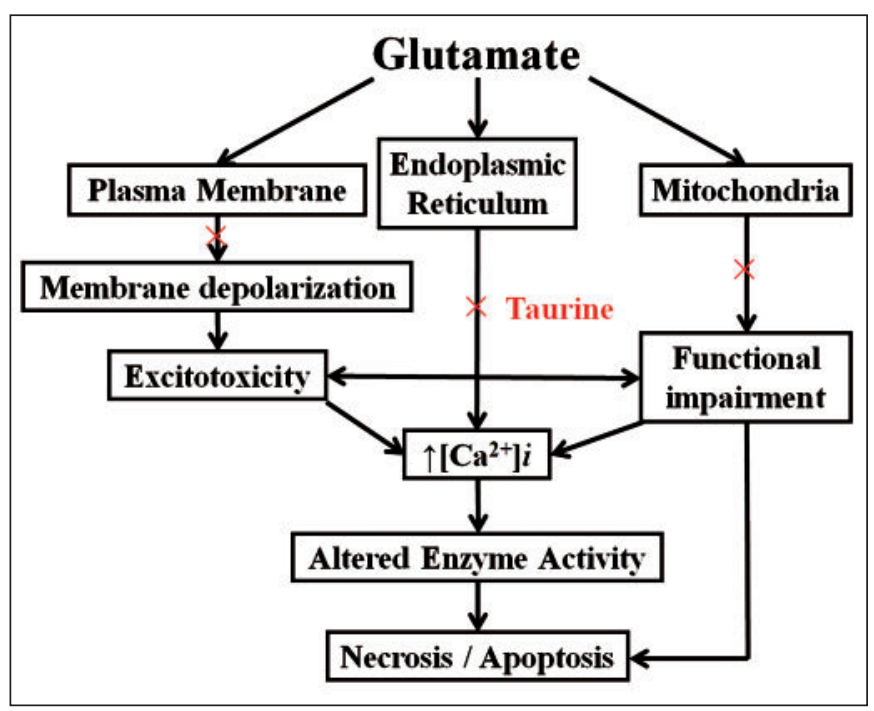

Figure: Schematic simplified overview of hypothesized pathophysiological mechanisms in the neuroprotective function of taurine (Tau) against Glu-induced neurotoxicity. Taurine protects neurons against Glu-induced neurotoxicity by preventing Glu-induced membrane depolarization, ER stress, mitochondrial energy failure and increased intracellular calcium levels. Increased intracellular calcium levels result in altered enzyme activities and together these activate directly or indirectly apoptotic pathways, or irreversible neuronal damage. The downstream events triggered by increased $[\mathrm{Ca} 2+]$ i leading from Glu stimulation, can be inhibited by taurine.

actions. We also know little about the possible taurine receptors when participate in protective against excitotoxicity. In particular, its critical roles in neuronal protection and underlying molecular mechanisms need to be carefully evaluated in relation to human neurological diseases. Further investigation of upstream signals controlling excitotoxicity afforded by taurine, and which cause hyperactivity of glu receptors under disease conditions may provide new insights on the mechanisms contributing to Glu-induced neurodegenerative diseases in humans, thereby unveiling novel strategies for therapy.

\section{ACKNOWLEDGMENTS}

This research was supported by the State Key Development Program for Basic Research of China (Grant no. 2011CB504503 and no. 2012CB967903), the National Science Foundation for Distinguished Young Scholars of China (Grant no. 30925035), Grants-in-Aid (no. 81170918 and no. 81170920) from the National Natural Science Foundation of China and Grant-in-Aid (No. 11JC1409700) from Shanghai Science and Technology Committee.

\section{REFERENCES}

1. Oja SS, Saransaari P. Pharmacology of taurine. Proc West Pharmacol Soc. 2007:50:8-15.

2. Sturman JA. Taurine in development. Physiol Rev. 1993;73(1): $119-47$.

3. Young TL, Cepko CL. A role for ligand-gated ion channels in rod photoreceptor development. Neuron. 2004;41(6):867-79.
4. Hayes KC, Carey RE, Schmidt SY. Retinal degeneration associated with taurine deficiency in the cat. Science. 1975;188(4191): 949-51.

5. Conte Camerino D, Tricarico D, Pierno S, et al. Taurine and skeletal muscle disorders. Neurochem Res. 2004;29(1):135-42.

6. Schaffer SW, Czarnecki CM, Cawthray M, Chovan JP. Cardiac taurine levels and sarcolemmal calcium binding activity in furazolidone-induced cardiomyopathy. Comp Biochem Physiol C. 1981;69C(1):149-51.

7. Pion PD, Kittleson MD, Rogers QR, Morris JG. Myocardial failure in cats associated with low plasma taurine: a reversible cardiomyopathy. Science. 1987;237(4816):764-8.

8. Ito T, Kimura Y, Uozumi Y, et al. Taurine depletion caused by knocking out the taurine transporter gene leads to cardiomyopathy with cardiac atrophy. J Mol Cell Cardiol. 2008; 44(5):927-37.

9. Wu JY. Purification and characterization of cysteic acid and cysteine sulfinic acid decarboxylase and L-glutamate decarboxylase from bovine brain. Proc Natl Acad Sci USA. 1982;79(14):4270-4

10. Lin CT, Song GX, Wu JY. Is taurine a neurotransmitter in rabbit retina? Brain Res. 1985;337(2):293-8.

11. Taber KH, Lin CT, Liu JW, Thalmann RH, Wu JY. Taurine in hippocampus: localization and postsynaptic action. Brain Res. 1986;386(1-2):113-21.

12. Okamoto K, Kimura H, Sakai Y. Taurine-induced increase of the Cl-conductance of cerebellar Purkinje cell dendrites in vitro. Brain Res. 1983;259(2):319-23.

13. Song NY, Shi HB, Li CY, Yin SK. Interaction between taurine and GABA(A)/glycine receptors in neurons of the rat anteroventral cochlear nucleus. Brain Res. 2012;1472:1-10.

14. Wu JY, Tang XW, Tsai WH. Taurine receptor: kinetic analysis and pharmacological studies. Adv Exp Med Biol. 1992;315:263-8.

15. Chesney RW, Zelikovic I, Jones DP, Budreau A, Jolly K. The renal transport of taurine and the regulation of renal sodium-chloridedependent transporter activity. Pediatr Nephrol. 1990;4(4): 399-407.

16. Li JH, Ling YQ, Fan JJ, Zhang XP, Cui S. Expression of cysteine sulfinate decarboxylase (CSD) in male reproductive organs of mice. Histochem Cell Biol. 2006;125(6):607-13.

17. Huxtable RJ. Physiological actions of taurine. Physiol Rev. 1992;72 (1):101-63.

18. Bouckenooghe T, Remacle C, Reusens B. Is taurine a functional nutrient? Curr Opin Clin Nutr Metab Care. 2006;9(6):728-33.

19. Moran J, Salazar P, Pasantes-Morales H. Effect of tocopherol and taurine on membrane fluidity of retinal rod outer segments. Exp Eye Res. 1987;45(6):769-76.

20. El Idrissi A. Taurine increases mitochondrial buffering of calcium: role in neuroprotection. Amino Acids. 2008;34(2):321-8.

21. Wu JY, Prentice H. Role of taurine in the central nervous system. J Biomed Sci. 2010;17 Suppl 1:S1.

22. Saransaari P, Oja SS. Release of GABA and taurine from brain slices. Prog Neurobiol. 1992;38(5):455-82.

23. Mutani R, Monaco F, Durelli L, Delsedime M. Levels of free amino acids in serum and cerebrospinal fluid after administration of taurine to epileptic and normal subjects. Epilepsia. 1975;16(5): 765-9.

24. Schaffer S, Takahashi K, Azuma J. Role of osmoregulation in the actions of taurine. Amino Acids. 2000;19(3-4):527-46.

25. Wade JV, Olson JP, Samson FE, Nelson SR, Pazdernik TL. A possible role for taurine in osmoregulation within the brain. $\mathrm{J}$ Neurochem. 1988;51(3):740-5.

26. Tang XW, Deupree DL, Sun Y, Wu JY. Biphasic effect of taurine on excitatory amino acid-induced neurotoxicity. Adv Exp Med Biol. 1996;403:499-505.

27. Azuma J, Takihara K, Awata N, et al. Taurine and failing heart: experimental and clinical aspects. Prog Clin Biol Res. 1985;179:195-213.

28. Smith LJ, Lacaille F, Lepage G, Ronco N, Lamarre A, Roy CC. Taurine decreases fecal fatty acid and sterol excretion in cystic fibrosis. A randomized double-blind trial. Am J Dis Child. 1991; 145(12):1401-4. 
29. Matsuyama Y, Morita T, Higuchi M, Tsujii T. The effect of taurine administration on patients with acute hepatitis. Prog Clin Biol Res. 1983;125:461-8.

30. Airaksinen EM, Oja SS, Marnela KM, Leino E, Pakkonen L. Effects of taurine treatment on epileptic patients. Prog Clin Biol Res. 1980;39:157-66.

31. Csernansky JG, Bardgett ME, Sheline YI, Morris JC, Olney JW. CSF excitatory amino acids and severity of illness in Alzheimer's disease. Neurology. 1996;46(6):1715-20.

32. Fonnum F. Glutamate: a neurotransmitter in mammalian brain. J Neurochem. 1984;42(1):1-11.

33. Hirai K, Yoshioka H, Kihara M, et al. Inhibiting neuronal migration by blocking NMDA receptors in the embryonic rat cerebral cortex: a tissue culture study. Brain Res Dev Brain Res. 1999; 114(1):63-7.

34. Ikonomidou C, Bosch F, Miksa M, et al. Blockade of NMDA receptors and apoptotic neurodegeneration in the developing brain. Science. 1999;283(5398):70-4.

35. Behar TN, Scott CA, Greene CL, et al. Glutamate acting at NMDA receptors stimulates embryonic cortical neuronal migration. J Neurosci. 1999;19(11):4449-61.

36. Wu G, Malinow R, Cline HT. Maturation of a central glutamatergic synapse. Science. 1996;274(5289):972-6.

37. Gurevich VS. [Taurine and the function of excitable tissues]. Fiziol Zh SSSR Im I M Sechenova. 1984;70(7):1046-56.

38. Bonfoco E, Krainc D, Ankarcrona M, Nicotera P, Lipton SA. Apoptosis and necrosis: two distinct events induced, respectively, by mild and intense insults with N-methyl-Daspartate or nitric oxide/superoxide in cortical cell cultures. Proc Natl Acad Sci USA. 1995;92(16):7162-6.

39. Lau A, Tymianski M. Glutamate receptors, neurotoxicity and neurodegeneration. Pflugers Arch. 2010;460(2):525-42.

40. Saransaari P, Oja SS. Taurine and neural cell damage. Amino Acids. 2000;19(3-4):509-26.

41. Wu JY, Wu H, Jin Y, et al. Mechanism of neuroprotective function of taurine. Adv Exp Med Biol. 2009;643:169-79.

42. Mankovskaya IN, Serebrovskaya TV, Swanson RJ, Vavilova GL, Kharlamova ON. Mechanisms of taurine antihypoxic and antioxidant action. High Alt Med Biol. 2000;1(2):105-10.

43. Jong CJ, Azuma J, Schaffer S. Mechanism underlying the antioxidant activity of taurine: prevention of mitochondrial oxidant production. Amino Acids. 2012;42(6):2223-32.

44. El Idrissi A, Trenkner E. Growth factors and taurine protect against excitotoxicity by stabilizing calcium homeostasis and energy metabolism. J Neurosci. 1999;19(21):9459-68.

45. Kocak-Toker N, Giris M, Tulubas F, Uysal M, Aykac-Toker G. Peroxynitrite induced decrease in $\mathrm{Na}+\mathrm{K}+$-ATPase activity is restored by taurine. World J Gastroenterol. 2005;11(23):3554-7.

46. Magalov Shl, Arzumanova KG. [Familial Friedreich's ataxia (review of foreign literature)]. Zh Nevropatol Psikhiatr Im S S Korsakova. 1989;89(3):136-41

47. Trenkner E, Liu D, Harris C, Sturman J. Regulation of protein kinase $\mathrm{C}$ activity by taurine and beta-alanine during excitotoxicity in cat and mouse cerebellar cultures. Adv Exp Med Biol. 1994;359:309-16.

48. Yu X, Xu Z, Mi M, et al. Dietary taurine supplementation ameliorates diabetic retinopathy via anti-excitotoxicity of glutamate in streptozotocin-induced Sprague-Dawley rats. Neurochem Res. 2008;33(3):500-7.

49. Wu H, Jin Y, Wei J, Jin H, Sha D, Wu JY. Mode of action of taurine as a neuroprotector. Brain Res. 2005;1038(2):123-31.

50. Bianchi L, Colivicchi MA, Ballini $\mathrm{C}$, et al. Taurine, taurine analogues, and taurine functions: overview. Adv Exp Med Biol. 2006;583:443-8

51. Foos TM, Wu JY. The role of taurine in the central nervous system and the modulation of intracellular calcium homeostasis. Neurochem Res. 2002;27(1-2):21-6.

52. Brustovetsky N, Dubinsky JM. Dual responses of CNS mitochondria to elevated calcium. J Neurosci. 2000;20(1): 103-13.

53. Khodorov B. Glutamate-induced deregulation of calcium homeostasis and mitochondrial dysfunction in mammalian central neurones. Prog Biophys Mol Biol. 2004;86(2):279-351.
54. Takatani T, Takahashi K, Uozumi Y, et al. Taurine inhibits apoptosis by preventing formation of the Apaf-1/caspase- 9 apoptosome. Am J Physiol Cell Physiol. 2004;287(4):C949-53.

55. Sun $M, X u$ C. Neuroprotective mechanism of taurine due to upregulating calpastatin and down-regulating calpain and caspase3 during focal cerebral ischemia. Cell Mol Neurobiol. 2008;28 (4):593-611.

56. Tenneti L, Lipton SA. Involvement of activated caspase-3-like proteases in $\mathrm{N}$-methyl-D-aspartate-induced apoptosis in cerebrocortical neurons. J Neurochem. 2000;74(1):134-42.

57. Bachis A, Colangelo AM, Vicini S, et al. Interleukin-10 prevents glutamate-mediated cerebellar granule cell death by blocking caspase-3-like activity. J Neurosci. 2001;21(9):3104-12.

58. Schinder AF, Olson EC, Spitzer NC, Montal M. Mitochondrial dysfunction is a primary event in glutamate neurotoxicity. J Neurosci. 1996;16(19):6125-33.

59. White RJ, Reynolds IJ. Mitochondrial depolarization in glutamatestimulated neurons: an early signal specific to excitotoxin exposure. J Neurosci. 1996;16(18):5688-97.

60. Green D, Kroemer G. The central executioners of apoptosis: caspases or mitochondria? Trends Cell Biol. 1998;8(7):267-71.

61. Gil-Parrado S, Fernandez-Montalvan A, Assfalg-Machleidt I, et al. Ionomycin-activated calpain triggers apoptosis. A probable role for Bcl-2 family members. J Biol Chem. 2002;277(30): 27217-26.

62. Gross A, McDonnell JM, Korsmeyer SJ. BCL-2 family members and the mitochondria in apoptosis. Genes Dev. 1999;13(15): 1899-911.

63. Choi DW, Rothman SM. The role of glutamate neurotoxicity in hypoxic-ischemic neuronal death. Annu Rev Neurosci. 1990;13: 171-82.

64. El Idrissi A, Trenkner E. Taurine as a modulator of excitatory and inhibitory neurotransmission. Neurochem Res. 2004;29(1): 189-97.

65. Takatani T, Takahashi K, Uozumi Y, et al. Taurine prevents the ischemia-induced apoptosis in cultured neonatal rat cardiomyocytes through Akt/caspase-9 pathway. Biochem Biophys Res Commun. 2004;316(2):484-9.

66. Wang GH, Jiang ZL, Fan XJ, Zhang L, Li X, Ke KF. Neuroprotective effect of taurine against focal cerebral ischemia in rats possibly mediated by activation of both GABAA and glycine receptors. Neuropharmacology. 2007;52(5):1199-209.

67. Taranukhin AG, Taranukhina EY, Saransaari P, Djatchkova IM, Pelto-Huikko M, Oja SS. Taurine reduces caspase- 8 and caspase-9 expression induced by ischemia in the mouse hypothalamic nuclei. Amino Acids. 2008;34(1):169-74.

68. Sun M, Gu Y, Zhao Y, Xu C. Protective functions of taurine against experimental stroke through depressing mitochondria-mediated cell death in rats. Amino Acids. 2011;40(5):1419-29.

69. Anelli T, Sitia R. Protein quality control in the early secretory pathway. EMBO J. 2008;27(2):315-27.

70. Ma Y, Hendershot LM. ER chaperone functions during normal and stress conditions. J Chem Neuroanat. 2004;28(1-2):51-65

71. Pizzo P, Pozzan T. Mitochondria-endoplasmic reticulum choreography: structure and signaling dynamics. Trends Cell Biol. 2007;17(10):511-7.

72. Azfer A, Niu J, Rogers LM, Adamski FM, Kolattukudy PE. Activation of endoplasmic reticulum stress response during the development of ischemic heart disease. Am J Physiol Heart Circ Physiol. 2006;291(3):H1411-20.

73. DeGracia DJ, Montie HL. Cerebral ischemia and the unfolded protein response. J Neurochem. 2004;91(1):1-8.

74. Nicholls D, Attwell D. The release and uptake of excitatory amino acids. Trends Pharmacol Sci. 1990;11(11):462-8.

75. Pan C, Prentice H, Price AL, Wu JY. Beneficial effect of taurine on hypoxia- and glutamate-induced endoplasmic reticulum stress pathways in primary neuronal culture. Amino Acids. 2012;43(2): 845-55.

76. Pan C, Gupta A, Prentice H, Wu JY. Protection of taurine and granulocyte colony-stimulating factor against excitotoxicity induced by glutamate in primary cortical neurons. J Biomed Sci. 2010;17 Suppl 1:S18. 
77. Jatzke C, Watanabe J, Wollmuth LP. Voltage and concentration dependence of $\mathrm{Ca}(2+)$ permeability in recombinant glutamate receptor subtypes. J Physiol. 2002 Jan 1;538(Pt 1):25-39.

78. Lazarewicz JW, Noremberg K, Lehmann A, Hamberger A. Effects of taurine on calcium binding and accumulation in rabbit hippocampal and cortical synaptosomes. Neurochem Int. 1985;7 (3):421-7.

79. Lombardini JB. Effects of taurine on calcium ion uptake and protein phosphorylation in rat retinal membrane preparations. J Neurochem. 1985;45(1):268-75.

80. Takahashi K, Azuma J, Awata N, et al. Protective effect of taurine on the irregular beating pattern of cultured myocardial cells induced by high and low extracellular calcium ion. J Mol Cell Cardiol. 1988;20(5):397-403.

81. Liu HY, Chi FL, Gao WY. Taurine modulates calcium influx under normal and ototoxic conditions in isolated cochlear spiral ganglion neurons. Pharmacol Rep. 2008;60(4):508-13.

82. Liu HY, Gao WY, Wen W, Zhang YM. Taurine modulates calcium influx through L-type voltage-gated calcium channels in isolated cochlear outer hair cells in guinea pigs. Neurosci Lett. 2006;399 (1-2):23-6.

83. Chen WQ, Jin H, Nguyen M, et al. Role of taurine in regulation of intracellular calcium level and neuroprotective function in cultured neurons. J Neurosci Res. 2001;66(4):612-9.

84. Takuma K, Matsuda T, Hashimoto H, Asano S, Baba A. Cultured rat astrocytes possess $\mathrm{Na}(+)-\mathrm{Ca} 2+$ exchanger. Glia. 1994;12(4): $336-42$.
85. Schaffer S, Azuma J, Takahashi K, Mozaffari M. Why is taurine cytoprotective? Adv Exp Med Biol. 2003;526:307-21.

86. Leon $\mathrm{R}, \mathrm{Wu} \mathrm{H}$, Jin $\mathrm{Y}$, et al. Protective function of taurine in glutamate-induced apoptosis in cultured neurons. J Neurosci Res. 2009;87(5):1185-94

87. Oja SS, Saransaari P. Modulation of taurine release by glutamate receptors and nitric oxide. Prog Neurobiol. 2000;62(4):407-25.

88. Saransaari P, Oja SS. Mechanisms of inhibitory amino acid release in the brain stem under normal and ischemic conditions. Neurochem Res. 2010;35(12):1948-56.

89. Duan Y, Gross RA, Sheu SS. Ca2+-dependent generation of mitochondrial reactive oxygen species serves as a signal for poly(ADP-ribose) polymerase-1 activation during glutamate excitotoxicity. J Physiol. 2007;585(Pt 3):741-58.

90. Araujo IM, Verdasca MJ, Leal EC, et al. Early calpain-mediated proteolysis following AMPA receptor activation compromises neuronal survival in cultured hippocampal neurons. J Neurochem. 2004;91(6):1322-31.

91. del Olmo N, Bustamante J, del Rio RM, Solis JM. Taurine activates GABA(A) but not GABA(B) receptors in rat hippocampal CA1 area. Brain Res. 2000;864(2):298-307.

92. Ricci L, Valoti M, Sgaragli G, Frosini M. Protection by taurine of rat brain cortical slices against oxygen glucose deprivation- and reoxygenation-induced damage. Eur J Pharmacol. 2009;621(13):26-32. 